\title{
Article \\ Nano Iron Oxide-PCL Composite as an Improved Soft Tissue Scaffold
}

\author{
Vahid Rezaei ${ }^{1}$, Esmaeil Mirzaei ${ }^{1, * \mathbb{D}}$, Seyedeh-Masoumeh Taghizadeh ${ }^{2}$, Aydin Berenjian ${ }^{3,4}$ \\ and Alireza Ebrahiminezhad 2,* \\ 1 Department of Medical Nanotechnology, School of Advanced Medical Sciences and Technologies, \\ Shiraz University of Medical Sciences, Shiraz P.O. Box 71348-14336, Iran; v_rezaei@sums.ac.ir \\ 2 Biotechnology Research Center, Shiraz University of Medical Sciences, Shiraz P.O. Box 71348-14336, Iran; \\ taghizm@sums.ac.ir \\ 3 School of Engineering, Faculty of Science and Engineering, University of Waikato, \\ Hamilton 3216, New Zealand; aydin.berenjian@waikato.ac.nz \\ 4 Department of Agricultural and Biological Engineering, 221 Agricultural Engineering Building, \\ Pennsylvania State University, State College, PA 16802, USA \\ * Correspondence: e_mirzaei@sums.ac.ir (E.M.); a_ebrahimi@sums.ac.ir (A.E.)
}

check for updates

Citation: Rezaei, V.; Mirzaei, E.; Taghizadeh, S.-M.; Berenjian, A.; Ebrahiminezhad, A. Nano Iron Oxide-PCL Composite as an Improved Soft Tissue Scaffold. Processes 2021, 9, 1559. https:// doi.org/10.3390/pr9091559

Academic Editor: Maurizio Ventre

Received: 19 April 2021

Accepted: 5 August 2021

Published: 1 September 2021

Publisher's Note: MDPI stays neutral with regard to jurisdictional claims in published maps and institutional affiliations.

Copyright: (c) 2021 by the authors. Licensee MDPI, Basel, Switzerland. This article is an open access article distributed under the terms and conditions of the Creative Commons Attribution (CC BY) license (https:// creativecommons.org/licenses/by/ $4.0 /)$.
Abstract: Iron oxide nanoparticles were employed to fabricate a soft tissue scaffold with enhanced physicochemical and biological characteristics. Growth promotion effect of L-lysine coated magnetite (Lys@ $\mathrm{Fe}_{3} \mathrm{O}_{4}$ ) nanoparticles on the liver cell lines was proved previously. So, in the current experiment these nanoparticles were employed to fabricate a soft tissue scaffold with growth promoting effect on the liver cells. Lys@ $\mathrm{Fe}_{3} \mathrm{O}_{4}$ nanoparticles were synthesized via co-precipitation reaction. Resulted particles were $\sim 7 \mathrm{~nm}$ in diameter and various concentrations $(3,5$, and $10 \mathrm{wt} \%)$ of these nanoparticles were used to fabricate nanocomposite PCL fibers. Electrospinning technique was employed and physicochemical characteristics of the resulted nanofibers were evaluated. Electron micrographs and EDX-mapping analysis showed that nanoparticles were well dispersed in the PCL fibers and no bead structure were formed. As expected, incorporation of Lys@ $\mathrm{Fe}_{3} \mathrm{O}_{4}$ to the PCL nanofibers resulted in a reduction in hydrophobicity of the scaffold. Nanocomposite scaffolds were shown increased tensile strength with increasing concentration of employed nanoparticles. In contrast to PCL scaffold, nearly 150\% increase in the cell viability was observed after 3-days exposure to the nanocomposite scaffolds. This study indicates that incorporation of magnetite nanoparticles in the PCL fibers make them more prone to cell attachment. However, incorporated nanoparticles can provide the attached cells with valuable iron element and consequently promote the cells growth rate. Based on the results, magnetite enriched PCL nanofibers could be introduced as a scaffold to enhance the biological performance for liver tissue engineering purposes.

Keywords: electrospinning; iron-enriched scaffold; magnetite nanoparticles; nanofiber; PCL scaffold; liver tissue engineering

\section{Introduction}

In recent years, tissue engineering (TE) has been recognized as a new approach in the biomedical sciences that focuses on repair, regeneration, and replacement of tissues [1]. TE consists of three fundamental portions including scaffolds, growth factors, and cells. By mimicking the extracellular matrix (ECM), scaffolds play the most important role in the TE techniques. Scaffolds with the help of growth factors provide a suitable site for cell attachment, growth, proliferation, and differentiation [2-7]. TE technologies have to overcome many limitations around the used scaffolds such as ineffective cell growth, inadequate production of effective growth factors, and inability to control cellular functions. Some scaffolds also suffer from poor biological, mechanical, and electrochemical properties. In addition, further studies and developments are required to achieve scaffolds with appropriate physiological structure [5]. 
Electrospinning is a well-known and simple technique for the construction of threedimensional biomimetic nano-scaffolds with hierarchical fibrous architecture [3,8-10]. Due to the structural similarity of electrospun fibrous to the ECM, electrospinning has become one of the most common techniques for the fabrication of TE scaffolds [11]. This technique provides scaffolds with a large surface area, good stability, high porosity, and pore interconnections [8-10,12].

Up to now, many natural and synthetic polymers have been used in electrospinning [7,13-15]. Natural polymers (e.g., alginate, gelatin, and collagen) have not been widely used alone due to weak mechanical strength and inappropriate degradation rate. Nonetheless, these compounds have been frequently used in composite scaffolds. Synthetic polymers with better mechanical properties than the natural ones are a good substitute to increase the biodegradability and biomechanical properties of scaffolds. Poly-lactic acid (PLA), poly (glycolic acid) (PGA), poly (lactic-co-glycolic acid) (PLGA), polyurethane (PU), and poly( $\varepsilon$-caprolactone) (PCL) are the most prevalent synthetic polymers used in electrospinning techniques [7]. PCL, as FDA approved polymer, has received much attention in this regard due to its tunable biodegradability and biocompatibility $[2,7,8,12,16,17]$. As with most other synthetic polymers, low hydrophilicity is one of the major disadvantages of PCL polymer and reduces the cell affinity to the resulting scaffolds [7,11]. The addition of hydrophilic compounds such as gelatin, collagen, and polyethylene glycol (PEG) is a common approach to increase hydrophilicity of PCL scaffolds [18-21]. In addition, metallic and non-metallic nanoparticles such as silver, chitosan, titanium oxide, silica, and magnetite nanoparticles were also incorporated in PCL scaffolds to improve physicochemical properties [6,22-26]. Magnetite nanoparticles are one of the well-studied nanoparticles to improve physicochemical and biological properties of PCL scaffolds. In all previous investigations however, magnetite nanoparticles loaded PCL scaffolds were employed just for efficient mesenchymal stem cell proliferation, bone regeneration, and drug delivery $[6,8,12,22,27]$. Meanwhile, in our previous investigation, we found that magnetite nanoparticles promote the growth of Hep-G2 cell line as well as human hepatic cell line. These nanoparticles can act as nano iron sources to increase hepatic cell growth and proliferation [28]. So, particularly in the case of liver scaffolds, in addition to beneficial effects on the physicochemical properties, it seems fortification with magnetite nanoparticles can provide a scaffold with growth-promoting effects. This hypothesis was investigated in the current study by developing composite nanofibers that are incorporated with magnetite nanoparticles (Scheme 1). Besides physicochemical evaluations, in vitro investigations were also performed on the Hep-G2 cells as a liver cell line. 


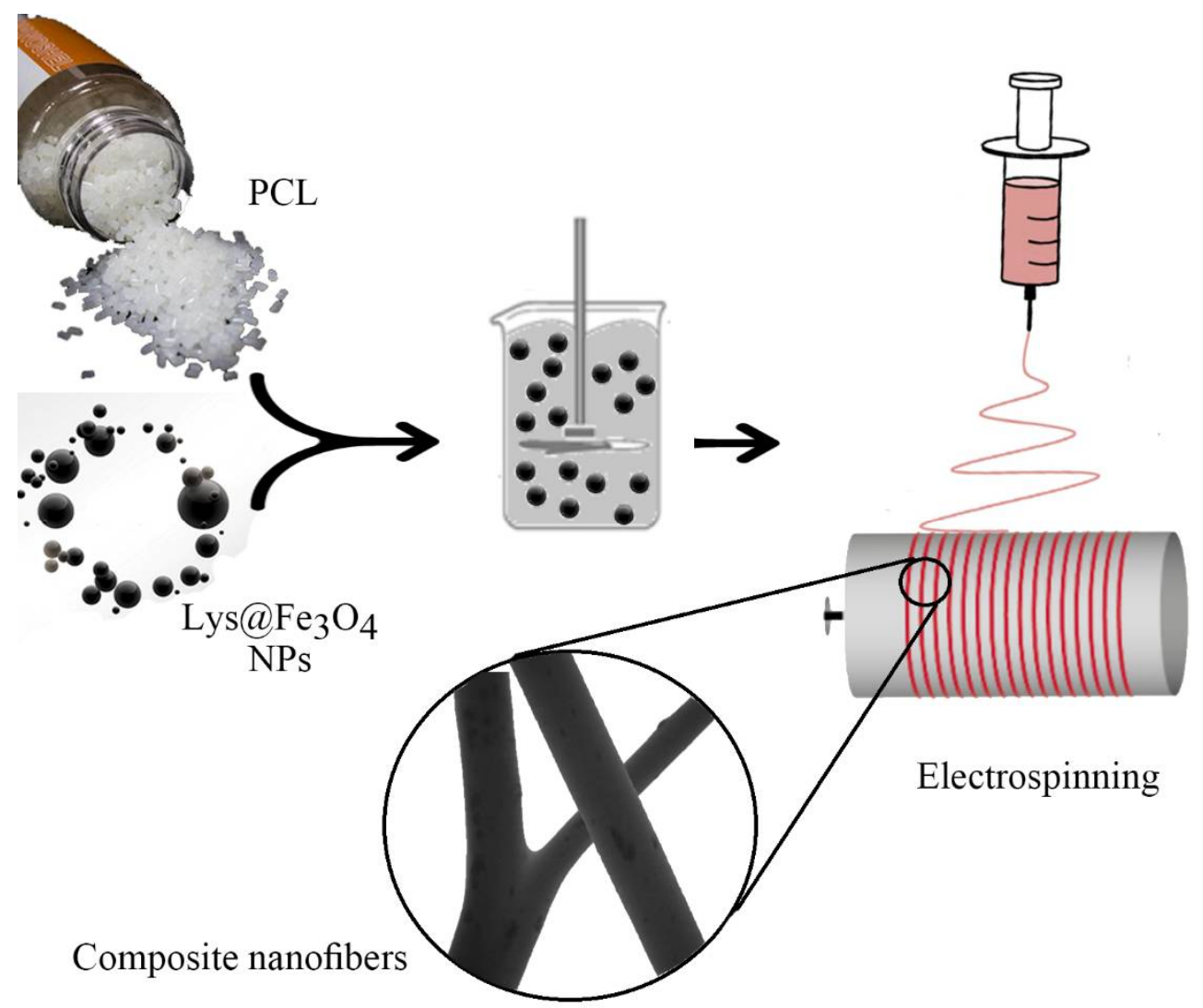

Scheme 1. Procedure for the fabrication of PCL nanofibers that were enriched with $\mathrm{Lys}_{\mathrm{F}} \mathrm{Fe}_{3} \mathrm{O}_{4}$ nanoparticles.

\section{Results}

2.1. Characterization of Nanoparticles

As shown in Figure 1, the XRD pattern of the synthesized lysine coated magnetite (Lys@ $@ \mathrm{Fe}_{3} \mathrm{O}_{4}$ ) nanoparticles represented characteristic peaks of magnetite at 30, 35.5, 43, 57, and 63 degrees in 2-Theta scale. The phase was identified by using PANalytical X'Pert HighScore Plus software version 3.0e (3.0.5) (PANalytical B.V., Almelo, The Netherlands) and COD databases bank. Analysis of the XRD graph was performed by using the Execute Search and Match tool under the Analysis menu and Magnetite 96-900-5839 reference code was the first phase candidate by 34 scores and all peaks were matched. Particle size analysis was done using the TEM micrographs and revealed that the $\mathrm{Lys} @ \mathrm{Fe}_{3} \mathrm{O}_{4}$ nanoparticles are in the range of $4-10 \mathrm{~nm}$ with an average size of $7 \mathrm{~nm}$ (Figure 2). FTIR evaluations were done in the region of 3800 to $400 \mathrm{~cm}^{-1}$ to investigate the chemical features of the nanoparticles. As shown in Figure 3, the strong band at $631 \mathrm{~cm}^{-1}$ is a characteristic peak for Fe-O bonds in the magnetic nanoparticles. Peaks of O-H groups appeared at $1621 \mathrm{~cm}^{-1}$ (deforming) and $3390 \mathrm{~cm}^{-1}$ (stretching). Peaks from $\mathrm{C}=\mathrm{O}$ and $\mathrm{N}-\mathrm{H}$ functional groups in the Lys coating were expected to appear at about $1630 \mathrm{~cm}^{-1}$ and $3000 \mathrm{~cm}^{-1}$, respectively. However, these peaks were overlapped with the peaks from $\mathrm{O}-\mathrm{H}$ deforming and stretching vibrations $[29,30]$. Previous studies showed that Lys and also other amino acids interact with the magnetite nanoparticles via their carbocycle groups and the side changes are exposed out of the nanoparticles [29-34]. 


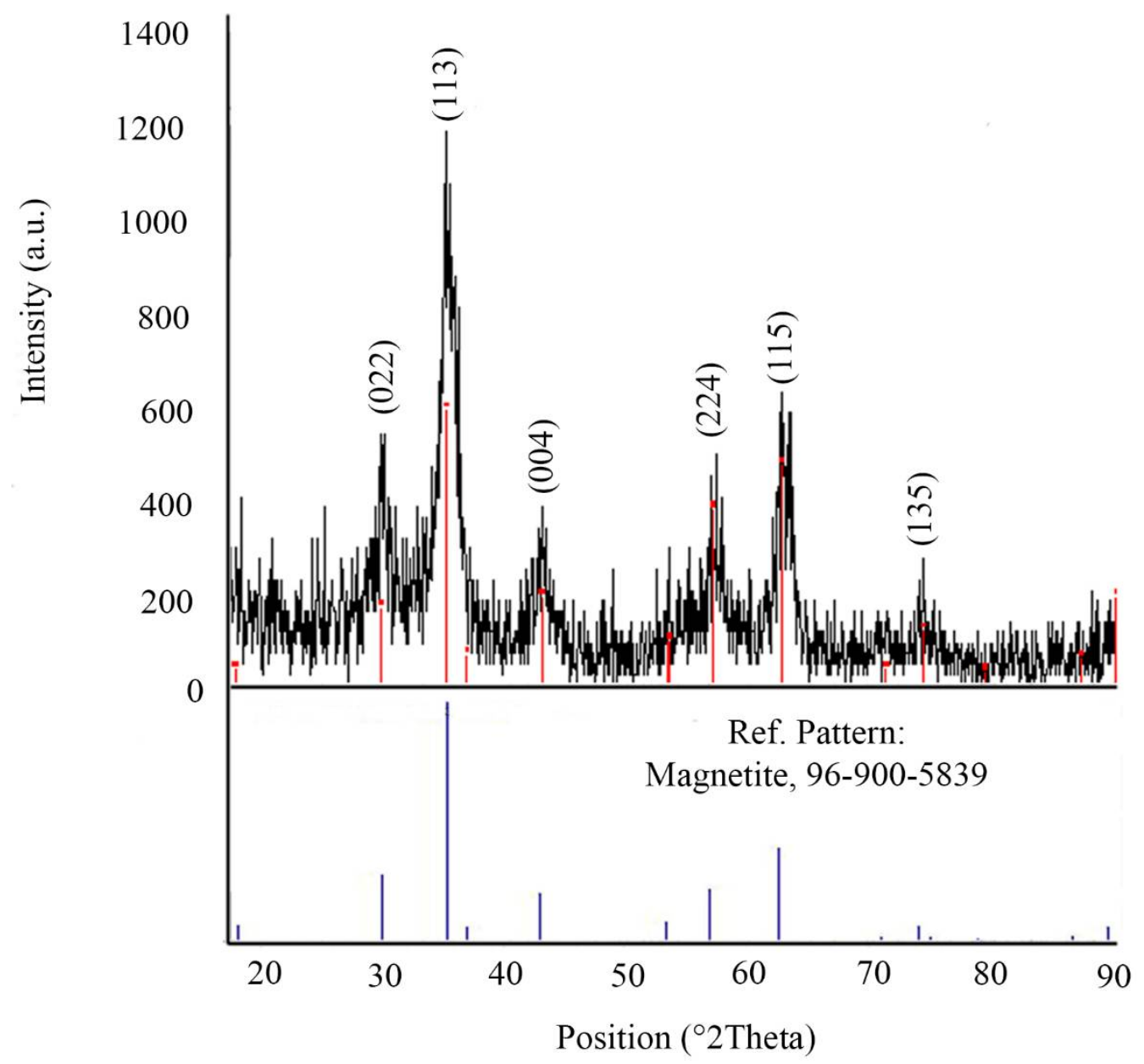

Figure 1. X-ray spectra of $\mathrm{Lys}_{\mathrm{O}} \mathrm{Fe}_{3} \mathrm{O}_{4}$ nanoparticles.

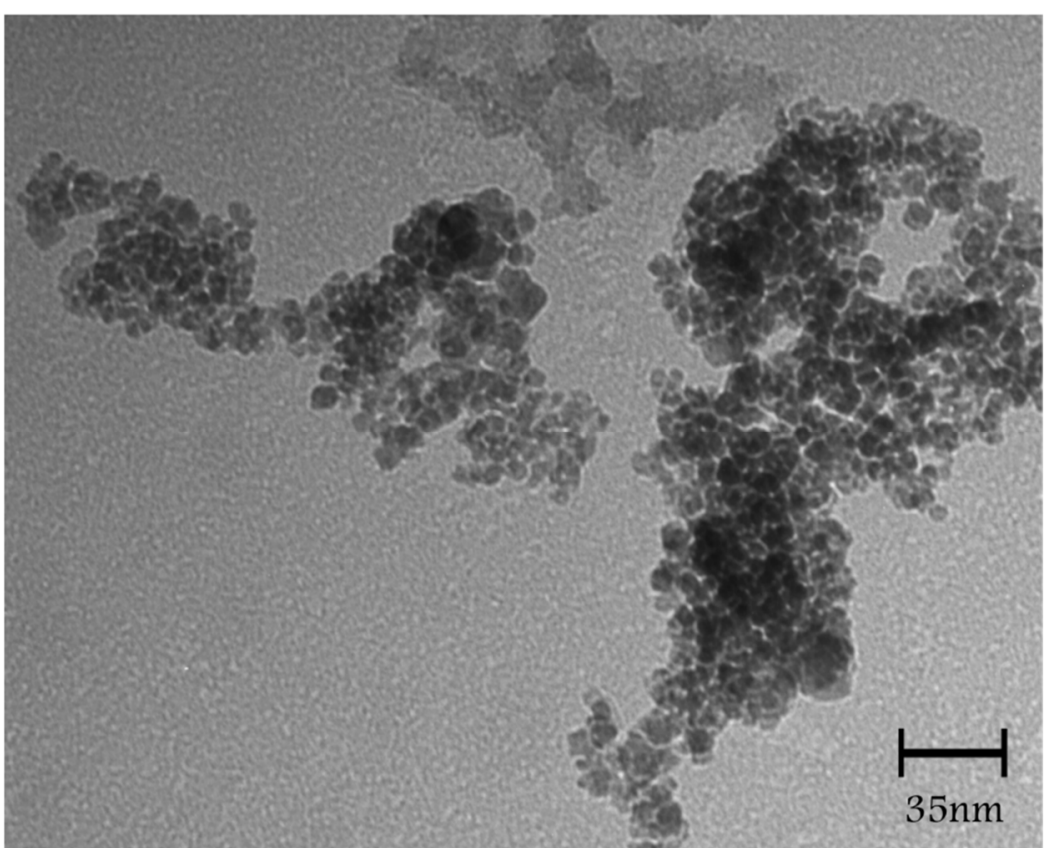

Figure 2. TEM image of the Lys@ $\mathrm{Fe}_{3} \mathrm{O}_{4}$ nanoparticles. 


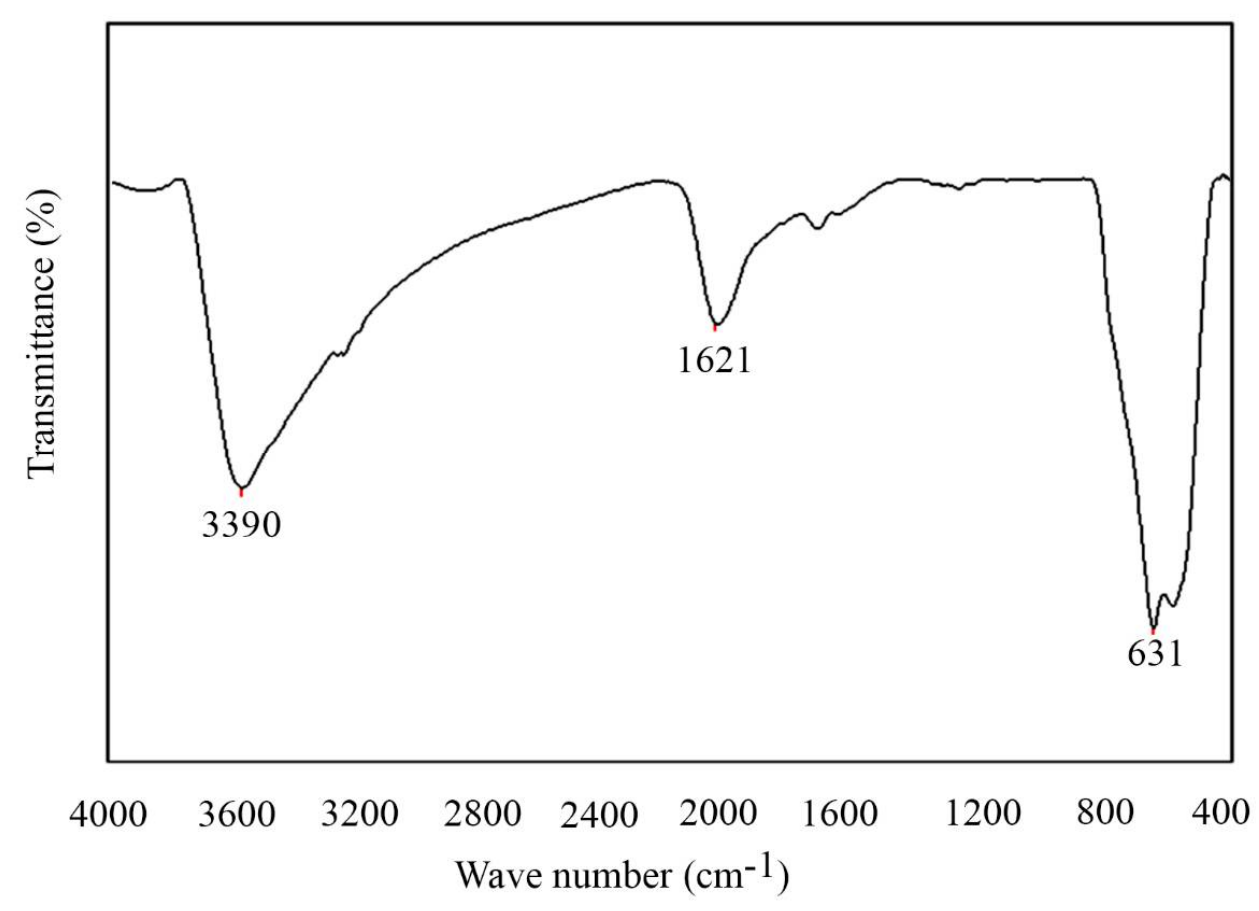

Figure 3. FTIR spectra of Lys@ $\mathrm{Fe}_{3} \mathrm{O}_{4}$ nanoparticles.

\subsection{Characterization of Scaffolds}

Appearance of the PCL nanocomposite fibrous mats with various concentrations ( 0 , 3, 5, and 10\%) of Lys@ $\mathrm{Fe}_{3} \mathrm{O}_{4}$ nanoparticles is illustrated in Figure 4. An increase in the nanoparticles concentration resulted in the darker brown membrane of fibers. SEM micrographs of the prepared fibers are provided in Figure 5 and illustrated a typical smooth and bead-free morphology. The diameters of the fibers were measured as $0.04-1.39 \mu \mathrm{m}$, 0.19-1.78 $\mu \mathrm{m}, 0.50-1.54 \mu \mathrm{m}$, and 0.65-1.59 $\mu \mathrm{m}$, for PCL, 3MNP, 5MNP, and 10MNP, respectively. The average fiber diameters (AFD) were calculated to be $0.719 \mu \mathrm{m}, 0.985 \mu \mathrm{m}$, $1.021 \mu \mathrm{m}$, and $1.122 \mu \mathrm{m}$, for PCL, 3MNP, 5MNP, and 10MNP, respectively. There are controversial data about the impacts of incorporated nanoparticles on the nanofiber diameter. Some investigations indicated that incorporation of nanoparticles (up to 15\%) in the PCL nanofibers resulted in a decrease in the fibers' diameter but an addition of $20 \%$ nanoparticles resulted in the fibers with increased diameter [6,8]. Effects of additives on the diameter of electrospun fibers can be related to the alterations in viscosity of the PCL solution. It is confirmed that increasing the viscosity of the electrospinning solution would subsequently result in larger nanofibers [35-37].

The elemental analysis of specimens was performed by SEM-EDX as shown in Figure 6. EDX mapping analysis collected evidence to confirm the existence and dispersion of magnetic nanoparticles in the fiber specimens. Three elements (iron, oxygen, and carbon) were evaluated in specimens and results are provided in Table 1. As expected, by increment of magnetic nanoparticles concentrations, an increase in the fibrous iron content was recorded.

ATR-FTIR spectra of the fiber specimens are shown in Figure 7 . The peaks that are due to functional groups in the PCL polymer appeared in 2943, 2865, 1722, 1240, and $1165 \mathrm{~cm}^{-1}$. The peaks at 2943 and $2865 \mathrm{~cm}^{-1}$ were due to asymmetric and symmetric stretching vibrations of $\mathrm{C}-\mathrm{H}$ bonds. The peak that is due to carbonyl groups stretching vibration appeared at $1722 \mathrm{~cm}^{-1}$. The peaks at $1240 \mathrm{~cm}^{-1}$ and $1165 \mathrm{~cm}^{-1}$ could be defined for $\mathrm{C}-\mathrm{C}$ and $\mathrm{C}-\mathrm{O}$ bonds, respectively. Moreover, the characteristic peak of iron oxide nanoparticles that is due to Fe-O stretching vibration was recorded at $583 \mathrm{~cm}^{-1}$ in the fibers that contain magnetite nanoparticles. Recorded data from the ATR-FTIR analysis were very similar to the previously reported spectra $[8,38,39]$. 


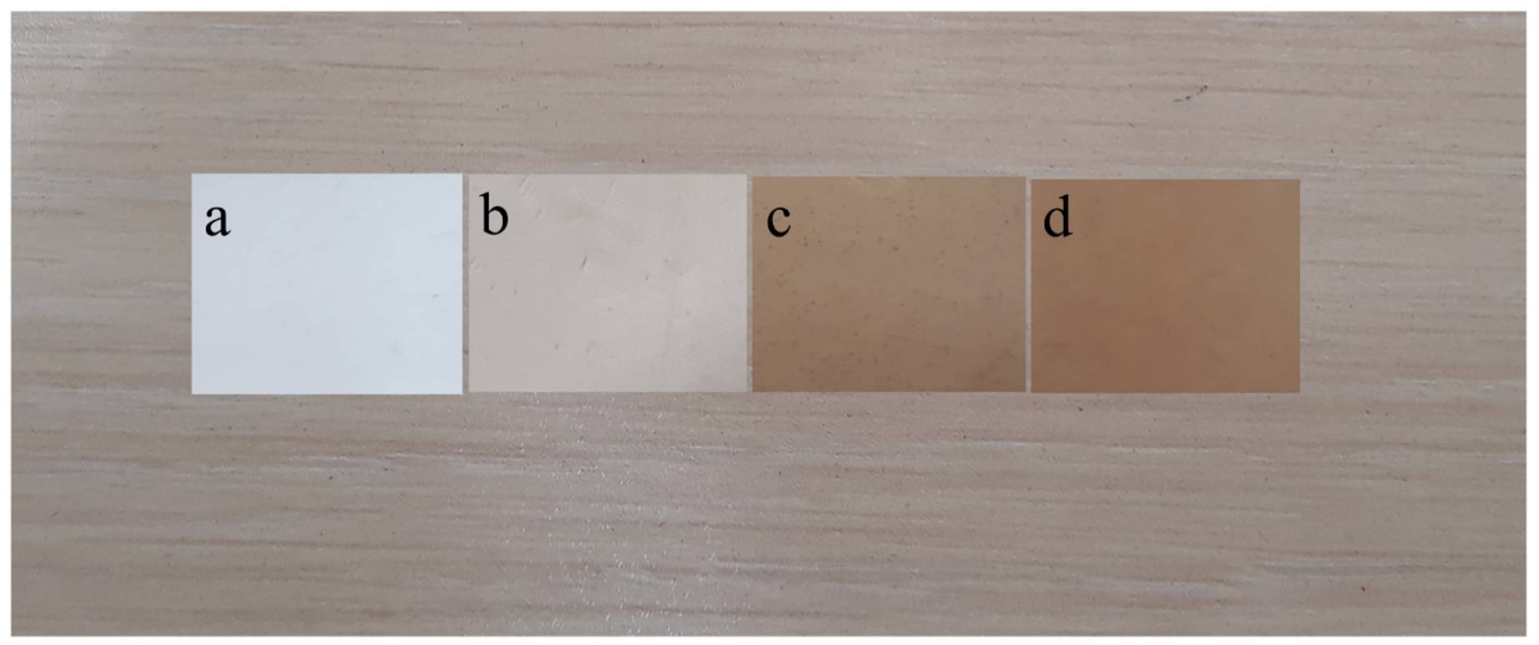

Figure 4. PCL and nanocomposite PCL fibrous scaffold membranes, (a): PCL, (b): 3MNP, (c): 5MNP, and (d): $10 \mathrm{MNP}$.

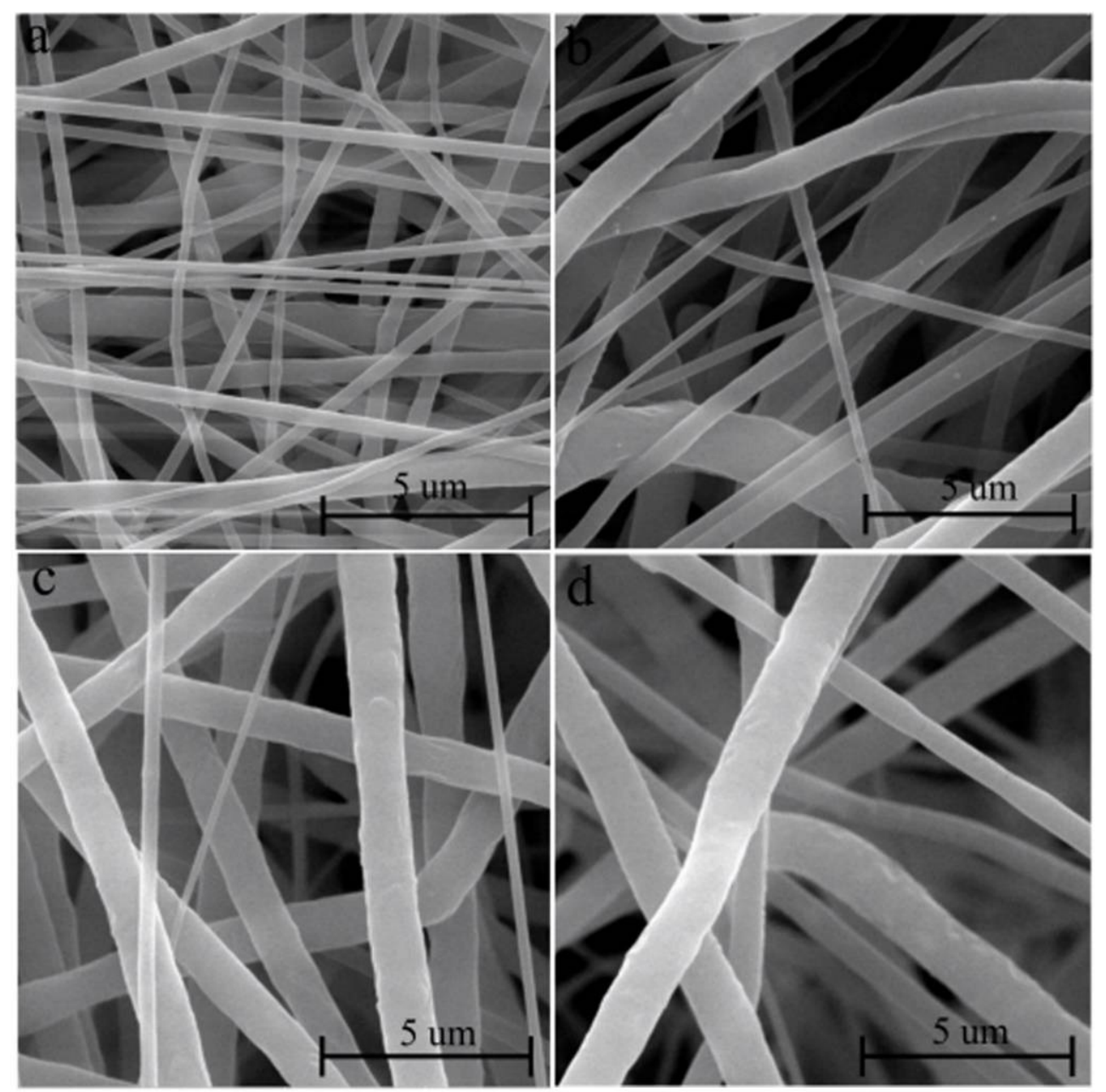

Figure 5. SEM micrographs of the fibrous scaffolds, (a): PCL, (b): $3 \mathrm{MNP},(\mathbf{c}): 5 \mathrm{MNP}$, and (d): 10MNP. 


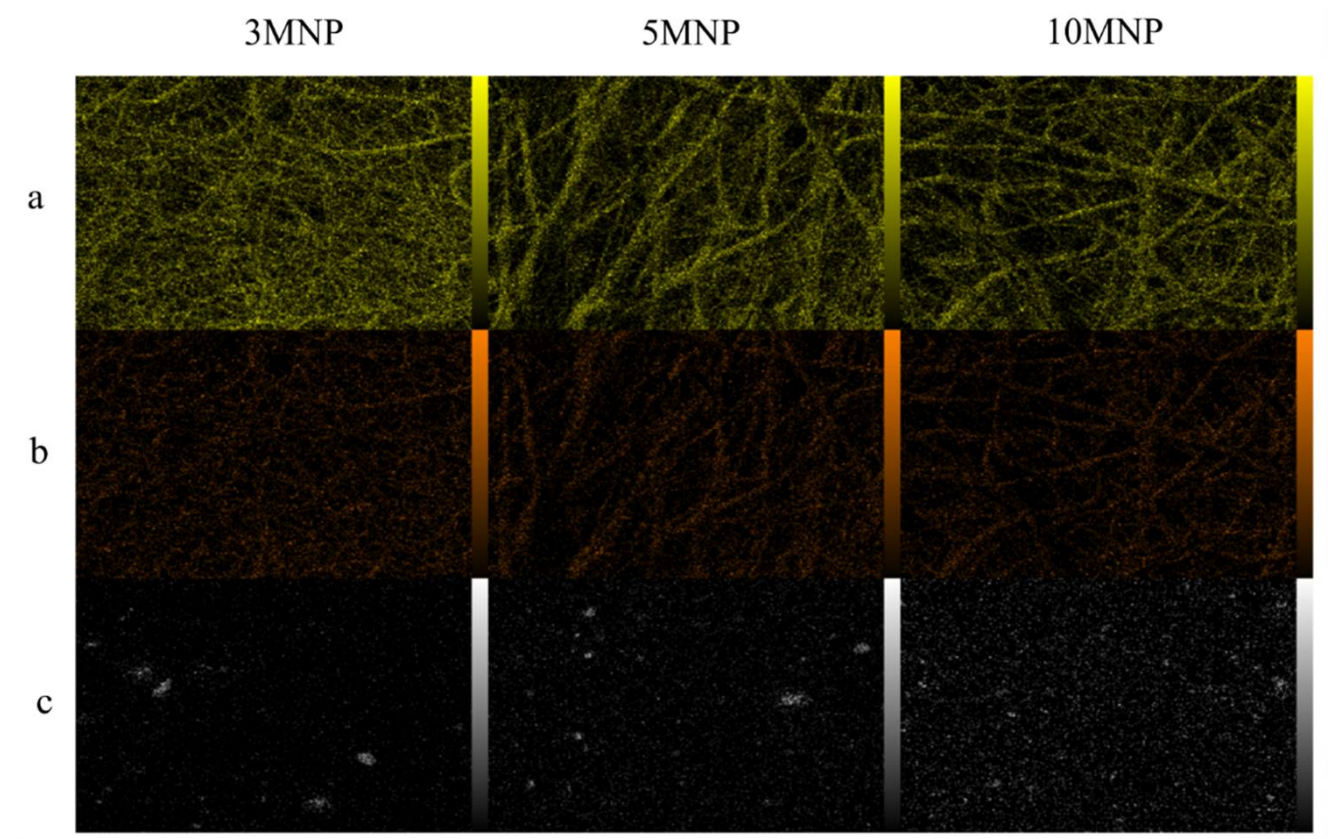

Figure 6. EDX-mapping analysis of nanoparticles incorporated scaffolds, (a): carbon, (b): oxygen, and (c): iron.

Table 1. Elemental content of the magnetite enriched PCL scaffolds resulted from EDX analysis.

\begin{tabular}{ccccccc}
\hline \multirow{2}{*}{ Elements } & \multicolumn{2}{c}{ 3MNP } & \multicolumn{2}{c}{ 5MNP } & \multicolumn{2}{c}{ 10MNP } \\
\cline { 2 - 7 } Composite & $\mathbf{A} \%$ & W\% & A \% & W\% & A\% & W\% \\
\hline Carbon & 73.19 & 66.93 & 72.34 & 65.53 & 72.88 & 65.77 \\
\hline Oxygen & 26.66 & 32.47 & 27.29 & 32.93 & 26.58 & 31.95 \\
\hline Iron & 0.15 & 0.6 & 0.36 & 1.53 & 0.54 & 2.27 \\
\hline
\end{tabular}

Abbreviations: A\%: Atomic percent; W\%: Weight percent.

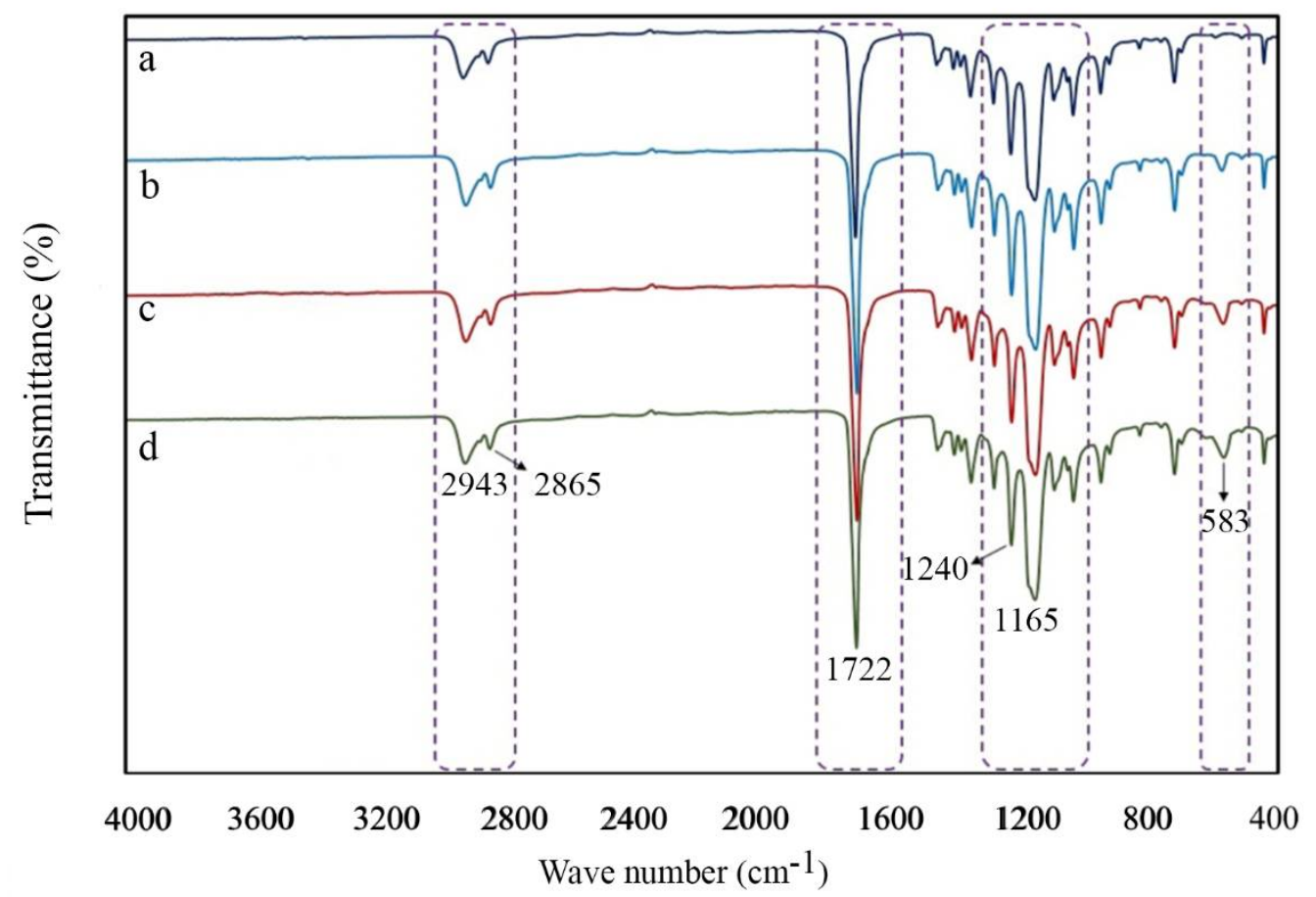

Figure 7. ATR-FTIR spectra of the fibrous scaffolds, (a): PCL, (b): $3 \mathrm{MNP},(\mathbf{c}): 5 \mathrm{MNP}$, and (d): 10MNP. 
The wettability of fibrous scaffolds was explored by contact angle testing (Figure 8). Incorporation of nanoparticles in the PCL polymer resulted in a concentration-dependent increase in the wettability of nanofibers. The contact angle of PCL fibers was measured to be $138.93^{\circ}$, while the angles for nanoparticles incorporated fibers were $132.21^{\circ}, 127.64^{\circ}$, and $121.5^{\circ}$ for $3 \mathrm{MNP}, 5 \mathrm{MNP}$, and $10 \mathrm{MNP}$, respectively. Previous investigations also showed magnetite nanoparticles have a concentration-dependent impact on the reduction of hydrophobicity of PCL nanofibers $[6,8]$.

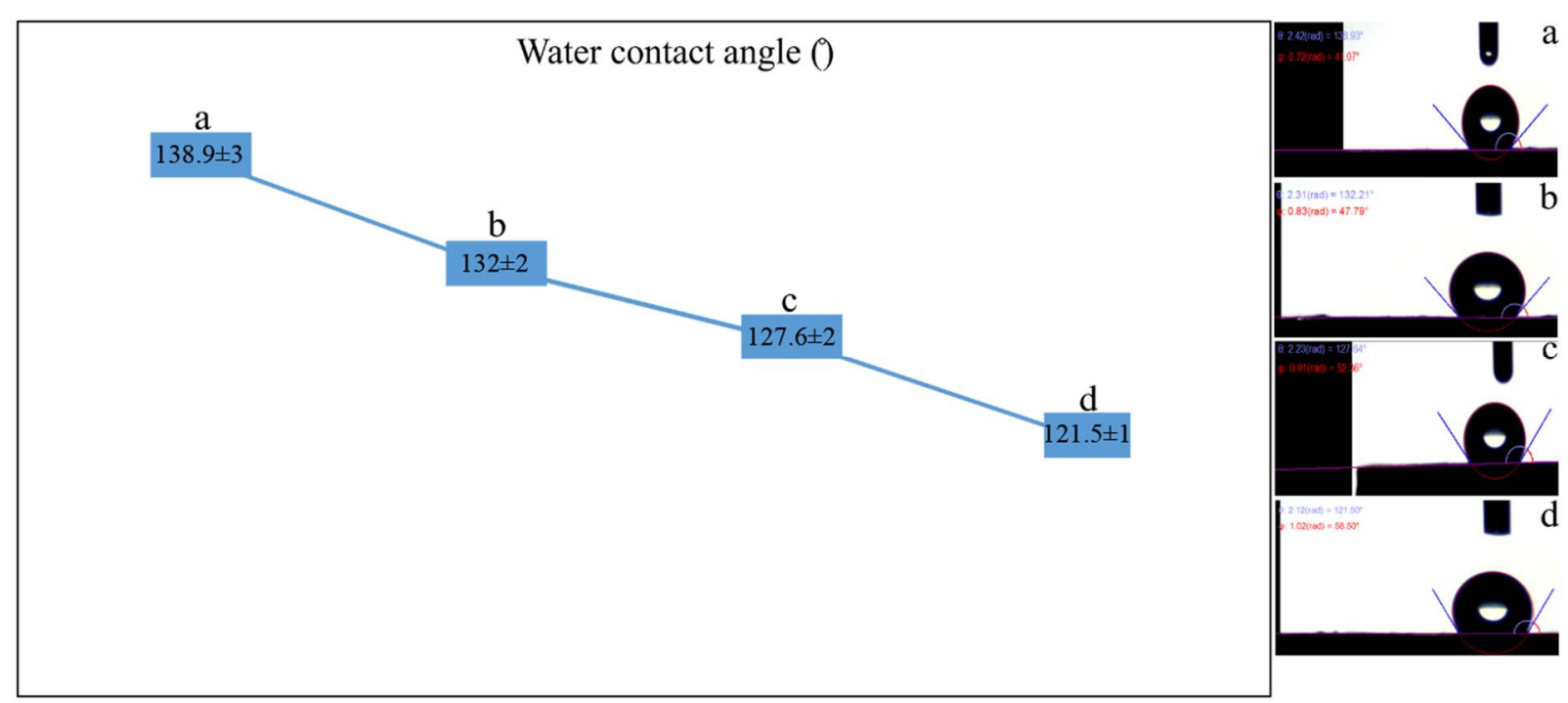

Figure 8. Contact angles of the fibrous scaffolds, (a): PCL, (b): $3 \mathrm{MNP},(\mathbf{c}): 5 \mathrm{MNP}$, and (d): $10 \mathrm{MNP}$, data were presented as mean \pm standard deviation (SD), $n=5$.

Results from tensile testing were presented as an overlaid diagram and presented in Figure 9. Other mechanical properties such as elastic module, elongation in peak point and elongation in break point are provided in Table 2. These data indicated that incorporation of magnetite nanoparticles in the PCL nanofibers resulted in a significant increase in the scaffold tensile strength. Increase in the scaffold strength was directly dependent on the concentration of employed nanoparticles. In the current experiment, magnetite nanoparticles were added to the PCL scaffolds up to $10 \mathrm{wt} \%$. Based on the results, it is obvious that high concentrations of incorporated nanoparticles can disturb the integrity of polymer fibers and hence reduce the tensile strength of the resulted scaffold [6]. Uniform dispersion of nanoparticles is the other critical point. Presence of beads in the fibers could possibly be due to nanoparticles agglomeration during the electrospinning process which will weaken the mechanical strength [40].

Table 2. Mechanical properties of fibrous scaffolds.

\begin{tabular}{ccccc}
\hline Samples & $\mathbf{F}(\mathbf{M P a})$ & $\mathbf{E}_{\text {mod }} \mathbf{( M P a )}$ & Elongation $_{\mathbf{p p}} \mathbf{( \% )}$ & Elongation $_{\mathbf{b p}} \mathbf{( \% )}$ \\
\hline PCL & $1.98 \pm 0.32$ & $2.95 \pm 0.66$ & $49.41 \pm 14$ & $57.64 \pm 16$ \\
\hline $3 \mathrm{MNP}$ & $2.21 \pm 0.37$ & $2.38 \pm 0.75$ & $72.96 \pm 17$ & $117.63 \pm 27$ \\
\hline $5 \mathrm{MNP}$ & $3.38 \pm 0.53$ & $4.42 \pm 0.9$ & $59.85 \pm 12$ & $93.87 \pm 23$ \\
\hline $10 \mathrm{MNP}$ & $4.9 \pm 0.62$ & $6.41 \pm 1.2$ & $62.71 \pm 13$ & $81.65 \pm 20$ \\
\hline
\end{tabular}

Abbreviations: F: tensile strength; E: elastic module; pp: peak point; bp: break point, data were presented as mean \pm standard deviation (SD), $n=3$. 


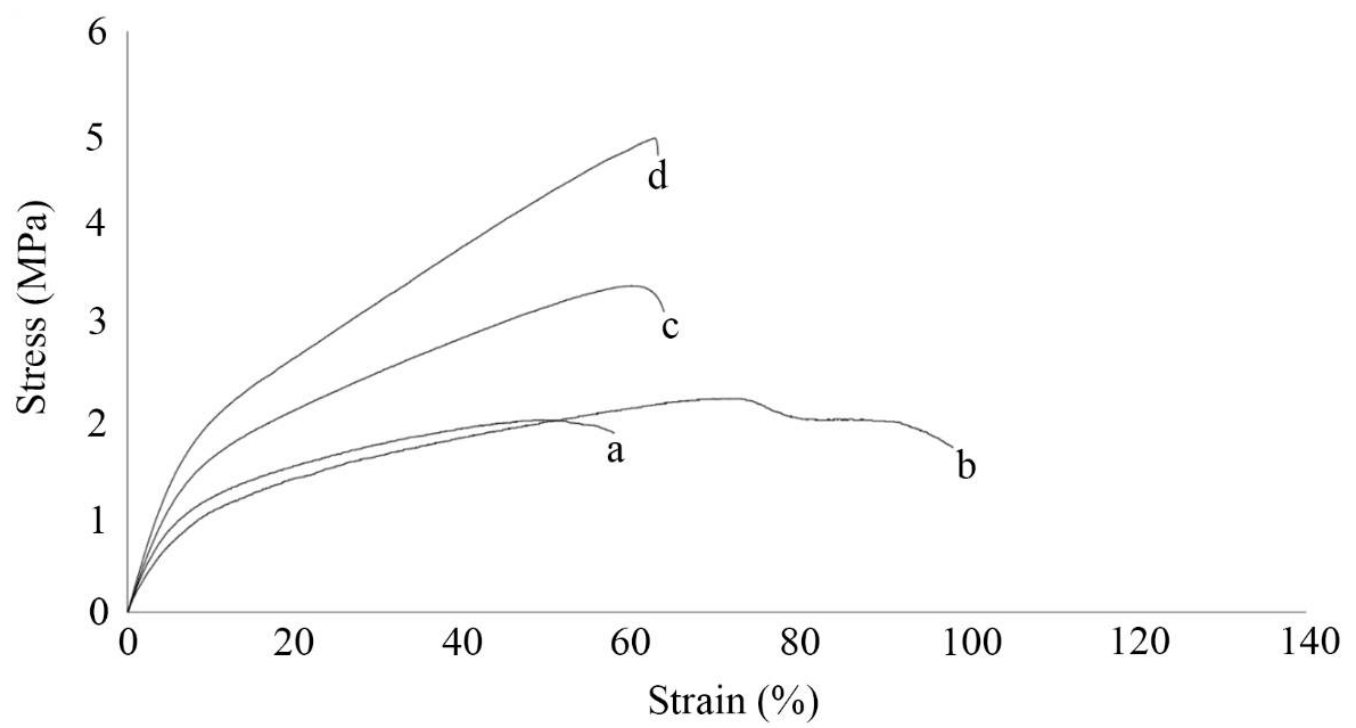

Figure 9. Tensile strength of the fibrous scaffolds, (a): PCL, (b): $3 \mathrm{MNP},(\mathbf{c})$ : $5 \mathrm{MNP}$, and (d): 10MNP.

Evaluations about the crystal structure of prepared nanofibers were performed by XRD analysis as shown in Figure 10. Due to the semi-crystalline nature of the PCL polymer, two sharp diffraction peaks were recorded from the PCL and nanoparticles incorporated PCL scaffolds. In the case of nanocomposite scaffold, the diffraction peaks from magnetite nanoparticles were considerably eliminated and just the sharpest peak of magnetite crystals at $35.5^{\circ}$ of 2-theta value was identifiable. These results indicated magnetite nanoparticles were completely embedded in the PCL fibers and there are no nanoparticles on the surface of fibers. Previous investigations about crystalline nanoparticles have shown similar observations. Coverage of crystalline nanoparticles with another crystalline material resulted in the elimination of diffraction peaks from the core structure [41]. Additionally, it is worth mentioning addition of magnetite nanoparticles to the PCL polymers reduced the sharpness of the PCL characteristic peaks. This finding indicated presence of nanoparticles in the fibers to some extent can disturb the crystal structure of the PCL polymer [42].

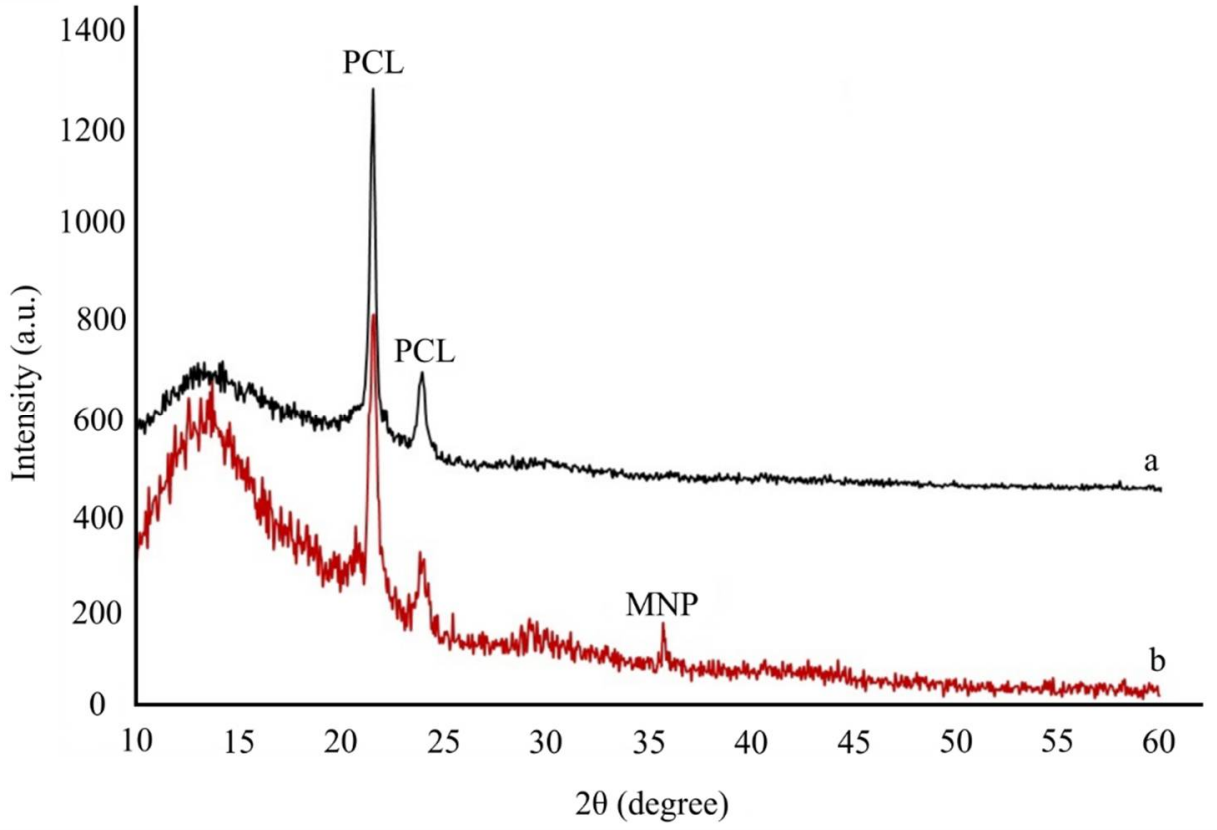

Figure 10. XRD patterns of PCL (a) and 5MNP (b) scaffolds. 
Transmission electron micrographs of the prepared nanofibers were depicted in Figure 11. No aggregation of magnetite nanoparticles was seen within the nanofibers; therefore, it could be assumed the mixture of magnetic nanoparticles and PCL polymer that was used in electrospinning process was a homogeneous suspension. While magnetic nanoparticles are not colloidally stable in the organic solvents, presence of PCL polymer can be considered as a key point to increase the stability of nanoparticles in the employed solvent system (chloroform/methanol). Similar observation was also reported in the previous study on the fabrication of magnetic nanofiber scaffolds [6].

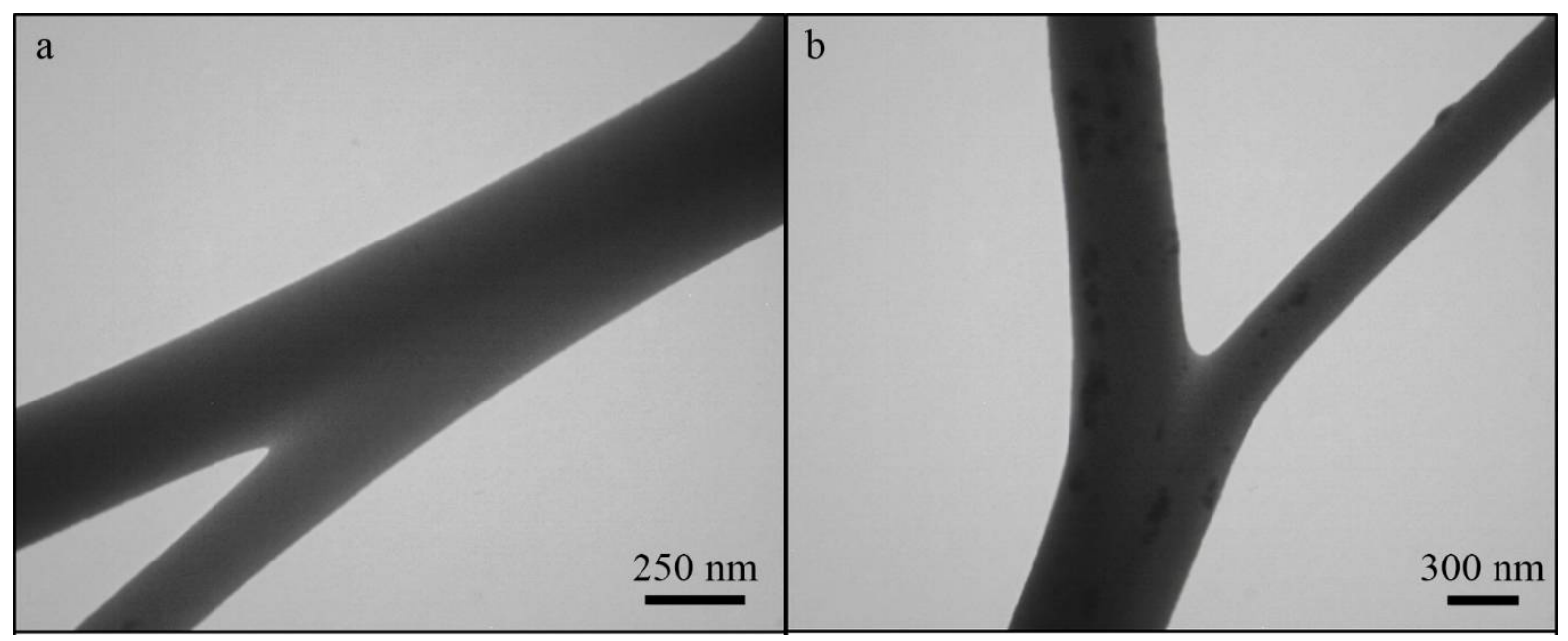

Figure 11. TEM images of PCL (a) and 5MNP (b) nanofibers.

TGA analysis was performed to evaluate thermal behavior of PCL and nanoparticles incorporated PCL nanofibers. As illustrated in Figure 12 major decomposition of PCL nanofibers was started at $340{ }^{\circ} \mathrm{C}$ and only $5.7 \%$ of the fibers remained at $440{ }^{\circ} \mathrm{C}$. Reduction in the weight continued at a very low rate up to $600^{\circ} \mathrm{C}$ and all the fibers were decomposed. Decomposition of nanocomposite fibers was started at $320^{\circ} \mathrm{C}$ and just $4.13 \%$ of the fiber remained at $\sim 360^{\circ} \mathrm{C}$. By increasing the temperature more than $360^{\circ}$, decomposition continued at a low rate and $1 \%$ remnant was recorded at $600{ }^{\circ} \mathrm{C}$. This remnant is claimed to be the remnant from magnetite nanoparticles. However, similar to previous reports the recorded value is not well-matched with the employed concentration of nanoparticles [6]. The effect of magnetite nanoparticles on the nanofibers' thermal stability was not found to be concentration-dependent. In fact, nanoparticles incorporated fibers were reported to be more thermally sensitive than PCL nanofibers and no obvious difference was reported for nanocomposites with various concentrations of nanoparticles [6].

\subsection{In Vitro Studies}

Metabolic activity and viability of Hep-G2 cells on the prepared nanofiber scaffolds were investigated over 1,3, and 5 days by MTT assay. Metabolic activity on the PCL scaffold was considered as a control (100\% viability) and measured activity on the nanoparticles incorporated scaffolds was reported as viability percent in contrast to control (Figure 13). After one day of exposure of Hep-G2 cells to nanofiber scaffolds no significant difference was seen among PCL and nanoparticles enriched PCL scaffolds. However, after three and five days of exposure to the scaffolds, more viability was recorded in the well that contained nanoparticles enriched nanofibers. 


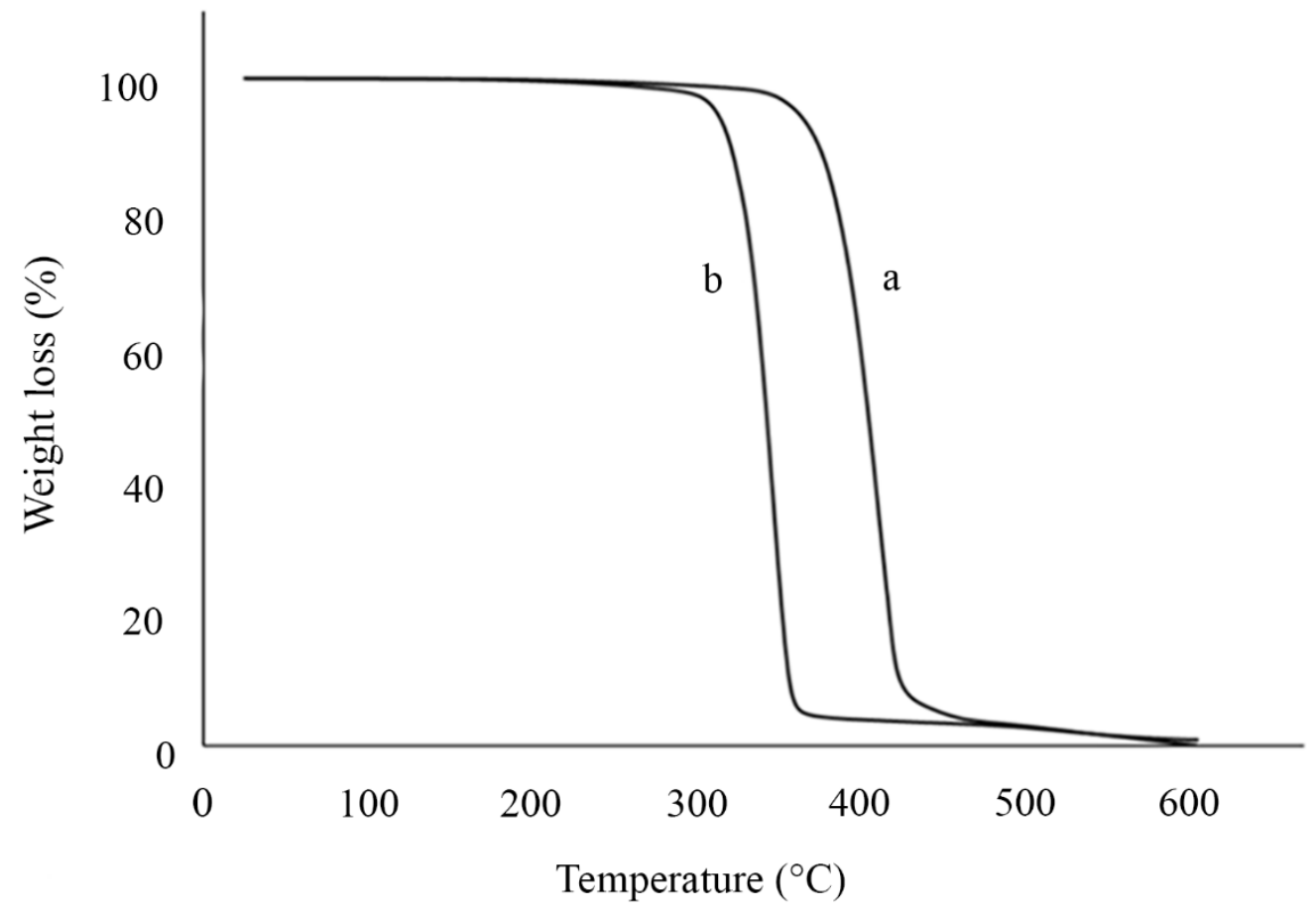

Figure 12. TGA analysis of PCL (a) and 5MNP (b) nanofibers.

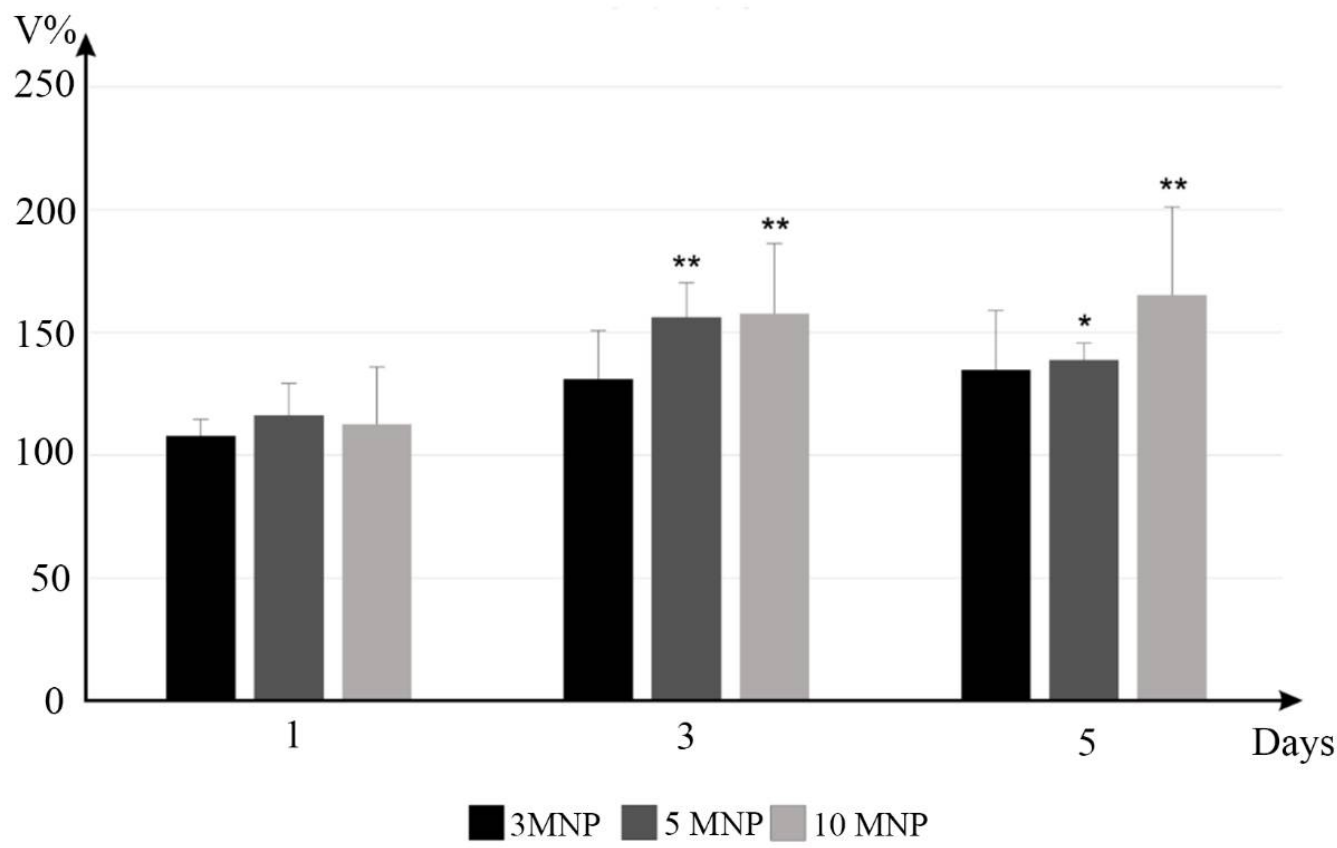

Figure 13. Viability of Hep-G2 cells over one, three, and five-days exposure to the magnetite enriched scaffolds, measured by MTT assay, data are represented as mean $\pm \mathrm{SD}(n=3)$, asterisks indicate significantly different as compared with the control group $\left({ }^{*} p<0.05\right.$ and $\left.{ }^{* *} p<0.01\right)$.

SEM was used to visualize the attachment of Hep-G2 cells on the prepared nanofibers. The investigation was performed after one and three-days exposure of cells to the nanofibers and resulting micrographs were provided in Figure 14. As expected, on the first day of exposure, cells retained their circular shape and did not tend to adhere to the scaffold. However, on the third day, the tendency of the cells to adhere on both PCL and nanoparticles enriched PCL scaffolds was increased and elongated flat cells were obviously identified. Due to the more hydrophilic nature of the nanoparticles enriched scaffolds, it can be con- 
cluded these scaffolds are more prone to cell colonization than PCL scaffolds. Additionally, it was observed the rate of elongation, expansion and even cell infiltration in the enriched scaffold was higher than the PCL scaffold.
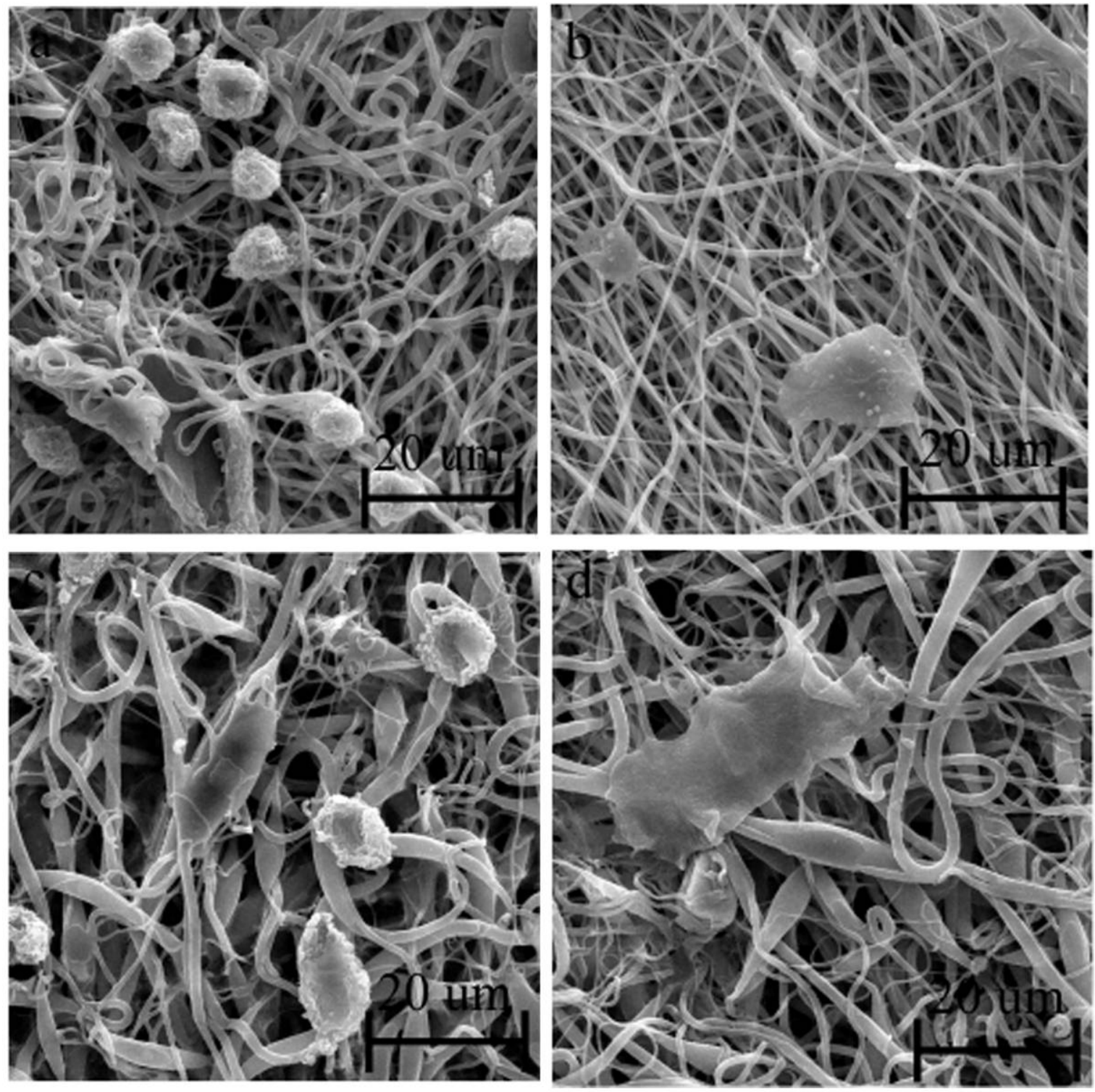

Figure 14. Cell attachment evaluations by SEM analysis, PCL fibers after one day (a) and three days (b) of cells seeding, $5 \mathrm{MNP}$ fibers after one day (c) and three days (d) of cells seeding.

\section{Discussion}

Previous investigations indicated that Lys@ $@ \mathrm{Fe}_{3} \mathrm{O}_{4}$ nanoparticles can promote cell growth and proliferation in the liver-originated cell lines [28]. Magnetite nanoparticles were also employed for the fortification of hard tissue scaffolds to achieve improved physical and chemical characteristics. In the current experiment, magnetite nanoparticles were used to fabricate a soft tissue scaffold with improved physicochemical characteristics and also enhanced biological functionalities. Magnetite nanoparticles embedded in the PCL nanofibers can act as iron nano-sources and provide the hepatic cells with the adequate iron for enhanced growth and metabolism. It is interesting that an increase in the biologic performance of the scaffolds can be up to $150 \%$. The scaffolds that were enriched with 5 or $10 \mathrm{wt} \%$ of nanoparticles provided significantly higher growth rate after three to five days of culture. In addition to iron supplementation, magnetite nanoparticles enhanced the 
hydrophilicity of PCL scaffolds and made the scaffolds more permeable to water dissolved nutrients. Additionally, more hydrophilic scaffold provides a better attachment site for the cells and results in an enhanced viability percent. These results are consistent with previous studies for application of composite PCL scaffolds for bone and dental tissue engineering $(6,12,22,34)$, but this investigation is the first effort for the fabrication of iron-enriched PCL nanofibers as a fortified soft tissue scaffold with enhanced biologic functionalities.

In addition to biological properties, incorporation of magnetite nanoparticles improves mechanical strength of the scaffolds. In this experiment, magnetite nanoparticles were added to the scaffold up to $10 \mathrm{wt} \%$ and it was seen that magnetite nanoparticles enhance tensile strength of the nanofibers. It has been shown higher concentrations $(20 \%)$ of nanoparticles can disturb the integrity of the fibers and reduce the tensile strength [6]. These data indicated there is an optimal concentration for the incorporated magnetite nanoparticles to maintain polymer accretion and it was revealed that addition of magnetite nanoparticles to the PCL nanofibers resulted in a reduction in the nanofibers' thermal stability. It seems magnetite nanoparticles acted as a nano-catalyst and enhanced the rate of polymer decomposition. On the other hand, reduction in the crystallinity can be the other reason to reduce thermal stability of nanocomposite fibers [43]. Based on the XRD data, incorporation of magnetite nanoparticles in the PCL nanofibers disturbed crystallinity of the PCL polymer and less sharp diffraction peaks were recorded. These results indicated that nanoparticles can reduce the crystallinity of PCL nanofibers and therefore reduce fibers' thermal resistance.

In addition to nanomaterials, there are several reports for the fortification of PCL nanofibers with phytochemicals, biomolecules, and even viruses. For instance, in an experiment curcumin-loaded PCL fibers were fabricated by melt and solution electrospinning methods. It was shown that the approach for the fibers' preparation has an immense impact on the pattern for the curcumin release. The fibers that were fabricated by melt electrospun had a low rate for curcumin release. Meanwhile, solution electrospinning provided fibers with a burst release profile. The difference in the drug release pattern was discussed to be due to the difference in the crystalline feature of the fibers [44]. Prolong drug, doxorubicin, release pattern was also reported by the PCL fibers with high crystallinity. The structure was designed to be a star polymer made up of a poly (amido-amine) (PAMAM) core and PCL branches. The structure exhibited effective controlled toxicity over A43, HeLa, and MCF-7 cells lines [45]. Drug-loaded PCL fibers were also employed as an efficient delivery system for vascular implant application. In this regard, PCL fibers were loaded with cilostazol to achieve a system for drug dissolution and diffusion in combination with polymer relaxation [46]. PCL nanofibers were also employed for the delivery of biomolecules such as microRNA. The delivery system was developed as a nanofiber-mediated microRNA delivery system to control cells differentiation through a combination of fiber topography and gene silencing [47]. Fortification of PCL nanofibers was not just performed by the chemicals or biomolecules and there are some experiments that used viral particles in this way. Localized transduction was reported to be performed by using a virus-encapsulated electrospun PCL fibrous scaffold. Recombinant adeno virus that encodes green fluorescent protein (GFP) was embedded in PCL fibers via co-axial electrospinning. Subsequently, the viral particles were released through a porogen-mediated process [48]. Bacteriophages were another viral particle that were employed for the fortification of PCL scaffolds. Bacteriophage capsids were covalently immobilized on the PCL nanofibers to maximize the phages' tail exposure and increase their antibacterial activity. Authors introduced the system as a promising substitute for antibiotics in applications toward skin infections [49]. These data from previous reports and the current experiment indicated PCL nanofibers can be employed as biocompatible and flexible fibers for selective fortification and fabrication of novel high throughput scaffolds. 


\section{Materials and Methods}

\subsection{Materials}

PCL (MW = 80,000 Da) and 3-(4,5-Dimethylthiazol-2-yl)-2,5-diphenyltetrazolium bromide (MMT) were obtained from Sigma-Aldrich (Darmstadt, Germany). Ferric chloride hexahydrate $\left(\mathrm{FeCl}_{3} \cdot 6 \mathrm{H}_{2} \mathrm{O}\right)$, Ferrous sulfate heptahydrate $\left(\mathrm{FeSO}_{4} \cdot 7 \mathrm{H}_{2} \mathrm{O}\right)$, ammonium hydroxide $\left(\mathrm{NH}_{4} \mathrm{OH}\right)$ and Lys were purchased from Merck (Darmstadt, Germany). Chloroform $\left(\mathrm{CHCl}_{3}\right)$ and methanol $\left(\mathrm{CH}_{3} \mathrm{OH}\right)$ were provided by Dr. Mojallali Chemical Complex (Tehran, Iran). Hep-G2 cell line was kindly provided by the Pharmaceutical Science Research Center, Shiraz University of Medical Sciences (Shiraz, Iran). Cell culture medium (RPMI-1640), trypsin, and fetal bovine serum (FBS) were also purchased from Gibco (Gibco Laboratories, Grand Island, NY, USA).

\subsection{Synthesis of Lys Coated Magnetite Nanoparticles}

Magnetite $\left(\mathrm{Fe}_{3} \mathrm{O}_{4}\right)$ nanoparticles were synthesized by co-precipitation reaction. Lys coating was also performed through the synthesis reaction via one-put reaction approach [32]. In brief, ferrous sulfate heptahydrate $\left(\mathrm{FeSO}_{4} \cdot 7 \mathrm{H}_{2} \mathrm{O}, 0.6 \mathrm{~g}\right)$ and ferric chloride hexahydrate $\left(\mathrm{FeCl}_{3} \cdot 6 \mathrm{H}_{2} \mathrm{O}, 1.7 \mathrm{~g}\right)$ were dissolved in $50 \mathrm{~mL}$ distilled water. The mixture was stirred under $\mathrm{N}_{2}$ atmosphere at $70{ }^{\circ} \mathrm{C}$ for $30 \mathrm{~min}$ and then Lys solution (1.6 g in $6 \mathrm{~mL}$ distilled water) was added. After another $30 \mathrm{~min}, 5 \mathrm{~mL} \mathrm{NH}_{4} \mathrm{OH}(32 \%)$ was suddenly injected into the reaction mixture and stirring continued for $1.5 \mathrm{~h}$. Resulted suspension of Lys coated magnetite $\left(\mathrm{Lys} @ \mathrm{Fe}_{3} \mathrm{O}_{4}\right.$ ) nanoparticles were harvested and washed with distilled water. The dark black precipitate was dried in an oven at $55^{\circ} \mathrm{C}$.

\subsection{Characterization of Lys Coated Magnetite Nanoparticles}

The crystallinity of Lys@ $\mathrm{Fe}_{3} \mathrm{O}_{4}$ nanoparticles was determined by X-ray diffraction (XRD, Siemens D5000, Siemens, Aubrey, TX, USA). The samples were scanned with $45 \mathrm{kV}$ and $40 \mathrm{~mA}$ current strength in a $2 \theta$ range of $10-60^{\circ}$ with a step size of $0.02^{\circ}$, and the rate of $2^{\circ} \mathrm{min}^{-1}$. Particle size analysis and morphology investigations were done by transmission electron microscopy (TEM; Philips, Amsterdam, Netherlands, CM 10, HT $100 \mathrm{Kv}$ ). Samples were prepared by drying a drop of nanoparticle suspension $(\sim 100 \mu \mathrm{g} / \mathrm{mL})$ on a carboncoated copper grid. Resulting micrographs were subjected to image analysis by using an open platform for scientific image analysis (ImageJ 1.47v software). Statistical analysis was also performed by SPSS Software v.20 (IBM Analytics, Chicago, IL, USA). Fourier transformed infrared spectroscopy (FT-IR; Bruker, Germany, Vertex 70) was performed with $\mathrm{KBr}$ pellets to determine the chemical status of the resulted nanoparticles.

\subsection{Preparation of PCL Nanofibers}

Nanoparticles doped PCL nanofibers were fabricated by dispersion of $\mathrm{Lys}_{\mathrm{O}} \mathrm{Fe}_{3} \mathrm{O}_{4}$ nanoparticles in the PCL solution prior to the electrospinning process. Briefly, $\mathrm{Lys}_{\mathrm{S}} \mathrm{Fe}_{3} \mathrm{O}_{4}$ nanoparticles were dispersed in a co-solvent of chloroform/methanol (3:1) and stirred for $2 \mathrm{~h}$. Then, PCL pellets $(9 \% w / w)$ were added to the suspension and stirring continued for $24 \mathrm{~h}$. The concentrations of nanoparticles were calculated to be 3,5 and $10 \mathrm{wt} \%$ of PCL. Resulted fibers were labeled as 3MNP, 5MNP, and 10MNP, respectively. Consequently, the mixture was loaded into a $5 \mathrm{~mL}$ syringe with 20-gauge needle and connected to a high-voltage $(11.5 \mathrm{kV})$ power supply of an electrospinning device (Nanoazma, Tehran, Iran). The distance of tip-to-collector was set to be $12 \mathrm{~cm}$, the flow rate was $0.8 \mathrm{~mL} / \mathrm{h}$, and the drum speed was $250 \mathrm{rpm}$. The process was performed at ambient atmosphere.

\subsection{Characterization of Fibers}

Scanning electron microscopy (SEM, TESCAN-Vega 3, Tescan, Brno, Czech Republic) at an accelerating voltage of $20 \mathrm{kV}$ was used to analyze 3D morphology of the PCL fibers. The image analysis was done by ImageJ software. Energy-dispersive X-ray spectroscopy (EDX) mapping evaluations were performed to visualize the pattern of elemental dispersion in nanofibers. Additionally, TEM (ZEISS EM10C-100 KV, Oberkochen, Germany) was used 
to visualize spread of nanoparticles in the fibers. Attenuated total reflection (ATR)-FTIR spectroscopy (Bruker, Tensor II, Germany) was used to determine the nanofibers' chemical profile. Water affinity was measured by water contact angle using the CA-500A analyzer (Sharifsolar, Iran). Tensile mechanical properties were measured by a universal testing instrument (SANTAM, STM-20; Navard, Iran). Small pieces $(30 \times 10 \mathrm{~mm})$ of fibers with a thickness of 150-300 $\mu \mathrm{m}$ were prepared and used for the mechanical test. Crystallinity of the fibers was characterized by XRD (Bruker, D8-ADVANCE) and samples were scanned in $2 \theta$ range of $10-60^{\circ}$ at the rate of $2^{\circ} \mathrm{min}^{-1}$. Studies about thermal behavior and compositional fraction of the fibers were accomplished by thermogravimetric analysis (TGA; Mettler Toledo, Switzerland).

\subsection{Cells Cultured and In Vitro Tests}

The Hep-G2 cells were cultured under the standard incubation conditions $\left(5 \% \mathrm{CO}_{2}\right.$, $37{ }^{\circ} \mathrm{C}$ ) using RPMI-1640 supplemented with 10\% FBS and 1\% pen/strep. Before any in vitro tests, scaffold specimens were sterilized by ultraviolet irradiation (30 min for each side of the film). Afterward, the specimens were attached to the bottom of the wells (48well-plate) using agarose solution $(0.5 \% w / w)$. Hep-G2 cells were incorporated in scaffold specimens and plates were incubated for 24 and $72 \mathrm{~h}$. Attached cells were fixed on the scaffolds by using $2.5 \%$ glutaraldehyde at room temperature. Specimens were then rinsed by PBS and dehydrated by 25,50,70, 95, and 100\% ethanol (three times and 5 min for each concentration). Afterwards, the specimens were evaluated via SEM.

MTT assay was used to evaluate cell viability and proliferation. After 24, 48, and $96 \mathrm{~h}$ incubation, attached wells were washed by PBS and incubated in MTT solution for $4 \mathrm{~h}$. Resulted blue formazan crystals were dissolved in $100 \mu \mathrm{L}$ DMSO and transferred into virgin wells for absorption measurement at $570 \mathrm{~nm}$ using a plate reader (Epoch, BioTek, Winooski, VT, USA).

\section{Conclusions}

Lys@ $\mathrm{Fe}_{3} \mathrm{O}_{4}$ nanoparticles were successfully employed as an additive to fabricate iron-enriched soft tissue PCL scaffolds. Incorporation of magnetite nanoparticles in the electrospun PCL fibers has an immense impact on the physical and chemical characteristics of the scaffolds. The particles made PCL scaffolds less hydrophobic and also increased the tensile strength of the fibers. On the other hand, composite nanofibers were more thermal sensitive than PCL nanofibers. TEM and EDX mapping analysis showed that nanoparticles were well dispersed in the nano fibers. Magnetite nanoparticles that were embedded in the nanofibers can act as valuable sources of iron to promote cell growth and proliferation. It is interesting that in contrast to the PCL scaffold, enriched scaffolds can improve cell viability up to $\sim 150 \%$. However, no considerable difference was observed in the cell attachment process. These data indicated that iron-enriched scaffolds can be considered as the scaffolds with increased biological performance for liver tissue engineering.

Author Contributions: Funding acquisition, A.E.; Investigation, V.R. and S.-M.T.; Methodology, V.R., E.M., S.-M.T. and A.E.; Project administration, E.M. and A.E.; Software, S.-M.T.; Supervision, E.M. and A.E.; Visualization, V.R. and A.E.; Writing-original draft, V.R.; Writing-review \& editing, A.B. and A.E. All authors have read and agreed to the published version of the manuscript.

Funding: This research was funded by the Shiraz University of Medical Sciences, Shiraz, Iran. The APC was funded by the University of Waikato, Hamilton, New Zealand.

Institutional Review Board Statement: The study was conducted according to the guidelines of the Declaration of Helsinki, and approved by the Ethics Committee of Shiraz University of Medical Sciences (approval ID: IR.SUMS.REC.1395.680, date of approval: 2019-07-23).

Informed Consent Statement: Not applicable.

Conflicts of Interest: The authors declare no conflict of interest. 


\section{References}

1. Edgar, L.; McNamara, K.; Wong, T.; Tamburrini, R.; Katari, R.; Orlando, G. Heterogeneity of Scaffold Biomaterials in Tissue Engineering. Materials 2016, 9, 332. [CrossRef] [PubMed]

2. Asvar, Z.; Mirzaei, E.; Azarpira, N.; Geramizadeh, B.; Fadaie, M. Evaluation of electrospinning parameters on the tensile strength and suture retention strength of polycaprolactone nanofibrous scaffolds through surface response methodology. J. Mech. Behav. Biomed. Mater. 2017, 75, 369-378. [CrossRef]

3. Fadaie, M.; Mirzaei, E.; Geramizadeh, B.; Asvar, Z. Incorporation of nanofibrillated chitosan into electrospun PCL nanofibers makes scaffolds with enhanced mechanical and biological properties. Carbohydr. Polym. 2018, 199, 628-640. [CrossRef]

4. Hammond, J.S.; Beckingham, I.J.; Shakesheff, K.M. Scaffolds for liver tissue engineering. Expert Rev. Med. Devices 2006, 3, 21-27. [CrossRef]

5. Hasan, A.; Morshed, M.; Memic, A.; Hassan, S.; Webster, T.J.; Marei, H.E.-S. Nanoparticles in tissue engineering: Applications, challenges and prospects. Int. J. Nanomed. 2018, 13, 5637-5655. [CrossRef]

6. Singh, R.K.; Patel, K.D.; Lee, J.H.; Lee, E.J.; Kim, J.H.; Kim, T.H.; Kim, H.W. Potential of magnetic nanofiber scaffolds with mechanical and biological properties applicable for bone regeneration. PLoS ONE 2014, 9, e91584. [CrossRef]

7. Bhattarai, D.P.; Aguilar, L.E.; Park, C.H.; Kim, C.S. A Review on Properties of Natural and Synthetic Based Electrospun Fibrous Materials for Bone Tissue Engineering. Membranes 2018, 8, 62. [CrossRef] [PubMed]

8. Demir, D.; Güreş, D.; Tecim, T.; Genç, R.; Bölgen, N. Magnetic nanoparticle-loaded electrospun poly ( $\varepsilon$-caprolactone) nanofibers for drug delivery applications. Appl. Nanosci. 2018, 8, 1461-1469. [CrossRef]

9. Jun, I.; Han, H.-S.; Edwards, J.R.; Jeon, H. Electrospun fibrous scaffolds for tissue engineering: Viewpoints on architecture and fabrication. Int. J. Mol. Sci. 2018, 19, 745. [CrossRef]

10. Lu, T.; Li, Y.; Chen, T. Techniques for fabrication and construction of three-dimensional scaffolds for tissue engineering. Int. J. Nanomed. 2013, 8, 337-350. [CrossRef]

11. Dulnik, J.; Denis, P.; Sajkiewicz, P.; Kołbuk, D.; Choińska, E. Biodegradation of bicomponent PCL/gelatin and PCL/collagen nanofibers electrospun from alternative solvent system. Polym. Degrad. Stab. 2016, 130, 10-21. [CrossRef]

12. Daňková, J.; Buzgo, M.; Vejpravova, J.; Kubíčková, S.; Sovková, V.; Vysloužilová, L.; Mantlíková, A.; Nečas, A.; Amler, E. Highly efficient mesenchymal stem cell proliferation on poly- $\varepsilon$-caprolactone nanofibers with embedded magnetic nanoparticles. Int. J. Nanomed. 2015, 10, 7307-7317. [CrossRef] [PubMed]

13. Manea, L.; Hristian, L.; Leon, A.; Popa, A. Recent advances of basic materials to obtain electrospun polymeric nanofibers for medical applications. IOP Conf. Ser. Mater. Sci. Eng. 2016, 145, 032006. [CrossRef]

14. Soares, R.M.; Siqueira, N.M.; Prabhakaram, M.P.; Ramakrishna, S. Electrospinning and electrospray of bio-based and natural polymers for biomaterials development. Mater. Sci. Eng. C 2018, 92, 969-982. [CrossRef] [PubMed]

15. Ding, J.; Zhang, J.; Li, J.; Li, D.; Xiao, C.; Xiao, H.; Yang, H.; Zhuang, X.; Chen, X. Electrospun polymer biomaterials. Prog. Polym. Sci. 2019, 90, 1-34. [CrossRef]

16. De Santis, R.; Gloria, A.; Russo, T.; d'Amora, U.; Zeppetelli, S.; Dionigi, C.; Sytcheva, A.; Herrmannsdörfer, T.; Dediu, V.; Ambrosio, L. A basic approach toward the development of nanocomposite magnetic scaffolds for advanced bone tissue engineering. J. Appl. Polym. Sci. 2011, 122, 3599-3605. [CrossRef]

17. Zhang, H.; Xia, J.; Pang, X.; Zhao, M.; Wang, B.; Yang, L.; Wan, H.; Wu, J.; Fu, S. Magnetic nanoparticle-loaded electrospun polymeric nanofibers for tissue engineering. Mater. Sci. Eng. C 2017, 73, 537-543. [CrossRef]

18. Hu, Y.; Feng, B.; Zhang, W.; Yan, C.; Yao, Q.; Shao, C.; Yu, F.; Li, F.; Fu, Y. Electrospun gelatin/PCL and collagen/PCL scaffolds for modulating responses of bone marrow endothelial progenitor cells. Exp. Ther. Med. 2019, 17, 3717-3726. [CrossRef]

19. Park, J.S.; Woo, D.G.; Sun, B.K.; Chung, H.M.; Im, S.J.; Choi, Y.M.; Park, K.; Huh, K.M.; Park, K.H. In vitro and in vivo test of PEG/PCL-based hydrogel scaffold for cell delivery application. J. Control. Release 2007, 124, 51-59. [CrossRef]

20. Ren, K.; Wang, Y.; Sun, T.; Yue, W.; Zhang, H. Electrospun PCL/gelatin composite nanofiber structures for effective guided bone regeneration membranes. Mater. Sci. Eng. C 2017, 78, 324-332. [CrossRef]

21. Zhou, Z.X.; Chen, Y.R.; Zhang, J.Y.; Jiang, D.; Yuan, F.Z.; Mao, Z.M.; Yang, F.; Jiang, W.B.; Wang, X.; Yu, J.K. Facile Strategy on Hydrophilic Modification of Poly( $\varepsilon$-caprolactone) Scaffolds for Assisting Tissue-Engineered Meniscus Constructs In Vitro. Front. Pharmacol. 2020, 11, 471. [CrossRef]

22. Kim, J.-J.; Singh, R.K.; Seo, S.-J.; Kim, T.-H.; Kim, J.-H.; Lee, E.-J.; Kim, H.-W. Magnetic scaffolds of polycaprolactone with functionalized magnetite nanoparticles: Physicochemical, mechanical, and biological properties effective for bone regeneration. RSC Adv. 2014, 4, 17325-17336. [CrossRef]

23. Ballesteros, C.A.; Correa, D.S.; Zucolotto, V. Polycaprolactone nanofiber mats decorated with photoresponsive nanogels and silver nanoparticles: Slow release for antibacterial control. Mater. Sci. Eng. C 2020, 107, 110334. [CrossRef] [PubMed]

24. Fahimirad, S.; Abtahi, H.; Satei, P.; Ghaznavi-Rad, E.; Moslehi, M.; Ganji, A. Wound healing performance of PCL/Chitosan based electrospun nanofiber electrosprayed with curcumin loaded chitosan nanoparticles. Carbohydr. Polym. 2021, 259, 117640. [CrossRef] [PubMed]

25. Rezk, A.I.; Bhattarai, D.P.; Park, J.; Park, C.H.; Kim, C.S. Polyaniline-coated titanium oxide nanoparticles and simvastatin-loaded poly ( $\varepsilon$-caprolactone) composite nanofibers scaffold for bone tissue regeneration application. Colloids Surf. B 2020, 192, 111007. [CrossRef] 
26. Gounani, Z.; Pourianejad, S.; Asadollahi, M.A.; Meyer, R.L.; Rosenholm, J.M.; Arpanaei, A. Polycaprolactone-gelatin nanofibers incorporated with dual antibiotic-loaded carboxyl-modified silica nanoparticles. J. Mater. Sci. 2020, 55, 17134-17150. [CrossRef]

27. Akbarzadeh, R.; Yousefi, A.M. Effects of processing parameters in thermally induced phase separation technique on porous architecture of scaffolds for bone tissue engineering. J. Biomed. Mater. Res. Part B 2014, 102, 1304-1315. [CrossRef]

28. Ebrahiminezhad, A.; Rasoul-Amini, S.; Kouhpayeh, A.; Davaran, S.; Barar, J.; Ghasemi, Y. Impacts of amine functionalized iron oxide nanoparticles on HepG2 cell line. Curr. Nanosci. 2015, 11, 113-119. [CrossRef]

29. Ebrahiminezhad, A.; Varma, V.; Yang, S.; Ghasemi, Y.; Berenjian, A. Synthesis and application of amine functionalized iron oxide nanoparticles on menaquinone-7 fermentation: A step towards process intensification. Nanomaterials 2015, 6, 1. [CrossRef]

30. Raee, M.J.; Ebrahiminezhad, A.; Gholami, A.; Ghoshoon, M.B.; Ghasemi, Y. Magnetic immobilization of recombinant E. coli producing extracellular asparaginase: An effective way to intensify downstream process. Sep. Sci. Technol. 2018, 53, 1397-1404. [CrossRef]

31. Ebrahiminezhad, A.; Ghasemi, Y.; Rasoul-Amini, S.; Barar, J.; Davaran, S. Impact of amino-acid coating on the synthesis and characteristics of iron-oxide nanoparticles (IONs). Bull. Korean Chem. Soc. 2012, 33, 3957-3962. [CrossRef]

32. Raee, M.J.; Ebrahiminezhad, A.; Ghoshoon, M.B.; Gholami, A.; Ghasemi, Y. Synthesis and characterization of L-lysin coated iron oxide nanoparticles as appropriate choices for cell immobilization and magnetic separation. Nanosci. Nanotechnology-Asia 2019, 9, 462-466. [CrossRef]

33. Durmus, Z.; Kavas, H.; Toprak, M.S.; Baykal, A.; Altincekic, T.G.; Aslan, A.; Bozkurt, A.; Cosgun, S. 1-lysine coated iron oxide nanoparticles: Synthesis, structural and conductivity characterization. J. Alloy. Compd. 2009, 484, 371-376. [CrossRef]

34. Patel, D.; Chang, Y.; Lee, G.H. Amino acid functionalized magnetite nanoparticles in saline solution. Curr. Appl. Phys. 2009, 9, S32-S34. [CrossRef]

35. Bortolassi, A.C.C.; Nagarajan, S.; de Araújo Lima, B.; Guerra, V.G.; Aguiar, M.L.; Huon, V.; Soussan, L.; Cornu, D.; Miele, P.; Bechelany, M. Efficient nanoparticles removal and bactericidal action of electrospun nanofibers membranes for air filtration. Mater. Sci. Eng. C 2019, 102, 718-729. [CrossRef] [PubMed]

36. Chen, X.; Zhang, Y.; He, X.; Li, H.; Wei, B.; Yang, W. Electrospinning on a plucked string. J. Mater. Sci. 2019, 54, 901-910. [CrossRef]

37. Petras, D.; Slobodian, P.; Pavlínek, V.; Sáha, P.; Kimmer, D. The effect of pvac solution viscosity on diameter of pvac nanofibres prepared by technology of electrospinning. AIP Conf. Proc. 2011, 1375, 312-319.

38. Bagheri, M.; Mahmoodzadeh, A. Polycaprolactone/Graphene Nanocomposites: Synthesis, Characterization and Mechanical Properties of Electrospun Nanofibers. J. Inorg. Organomet. Polym. Mater. 2020, 30, 1566-1577. [CrossRef]

39. Ramírez-Cedillo, E.; Ortega-Lara, W.; Rocha-Pizaña, M.R.; Gutierrez-Uribe, J.A.; Elías-Zúñiga, A.; Rodríguez, C.A. Electrospun Polycaprolactone Fibrous Membranes Containing $\mathrm{Ag}, \mathrm{TiO}_{2}$ and $\mathrm{Na}_{2} \mathrm{Ti}_{6} \mathrm{O}(13)$ Particles for Potential Use in Bone Regeneration. Membranes 2019, 9, 12. [CrossRef]

40. Huang, Z.-M.; Zhang, Y.; Ramakrishna, S.; Lim, C. Electrospinning and mechanical characterization of gelatin nanofibers. Polymer 2004, 45, 5361-5368. [CrossRef]

41. Taghizadeh, S.-M.; Berenjian, A.; Taghizadeh, S.; Ghasemi, Y.; Taherpour, A.; Sarmah, A.K.; Ebrahiminezhad, A. One-put green synthesis of multifunctional silver iron core-shell nanostructure with antimicrobial and catalytic properties. Ind. Crop. Prod. 2019, 130, 230-236. [CrossRef]

42. Meng, Z.; Zheng, W.; Li, L.; Zheng, Y. Fabrication and characterization of three-dimensional nanofiber membrance of PCLMWCNTs by electrospinning. Mater. Sci. Eng. C 2010, 30, 1014-1021. [CrossRef]

43. Daniel, C.; Zhovner, D.; Guerra, G. Thermal stability of nanoporous crystalline and amorphous phases of poly (2, 6-dimethyl-1, 4-phenylene) oxide. Macromolecules 2013, 46, 449-454. [CrossRef]

44. Lian, H.; Meng, Z. Melt electrospinning vs. solution electrospinning: A comparative study of drug-loaded poly ( $\varepsilon$-caprolactone) fibres. Mater. Sci. Eng. C 2017, 74, 117-123. [CrossRef] [PubMed]

45. Balakrishnan, P.B.; Gardella, L.; Forouharshad, M.; Pellegrino, T.; Monticelli, O. Star poly ( $\varepsilon$-caprolactone)-based electrospun fibers as biocompatible scaffold for doxorubicin with prolonged drug release activity. Colloids Surf. B 2018, 161, 488-496. [CrossRef]

46. Rychter, M.; Baranowska-Korczyc, A.; Milanowski, B.; Jarek, M.; Maciejewska, B.M.; Coy, E.L.; Lulek, J. Cilostazol-loaded poly ( $\varepsilon$-Caprolactone) electrospun drug delivery system for cardiovascular applications. Pharm. Res. 2018, 35, 32. [CrossRef]

47. Diao, H.J.; Low, W.C.; Milbreta, U.; Lu, Q.R.; Chew, S.Y. Nanofiber-mediated microRNA delivery to enhance differentiation and maturation of oligodendroglial precursor cells. J. Control. Release 2015, 208, 85-92. [CrossRef]

48. Liao, I.-C.; Chen, S.; Liu, J.B.; Leong, K.W. Sustained viral gene delivery through core-shell fibers. J. Control. Release 2009, 139, 48-55. [CrossRef]

49. Nogueira, F.; Karumidze, N.; Kusradze, I.; Goderdzishvili, M.; Teixeira, P.; Gouveia, I.C. Immobilization of bacteriophage in wound-dressing nanostructure. Nanomedicine 2017, 13, 2475-2484. [CrossRef] [PubMed] 